\title{
PERSPECTIVAS SOBRE O USO DE METODOLOGIAS ATIVAS NO CONTEXTO DA CULTURA DIGITAL
}

\section{Perspectives on the Use Of Methodologies Active in the Context Of Digital Culture}

\author{
Maiara Lenine Bakalarczyk Corrêa* \\ Cintia Inês Boll**
}

\begin{abstract}
Resumo: Frente aos desafios atuais da educação em contexto de cultura digital e de sociedade da informação, é importante pensar sobre as abordagens metodológicas utilizadas em sala de aula de modo a oportunizar a formação de um estudante atuante sobre esse contexto social e cultural. Nesse sentido, as metodologias ativas demonstram possibilidades de trabalho onde o estudante pode ter ação autônoma, criativa e exploradora do aprendizado fortalecido pelo suporte do professor enquanto mediador e questionador. O presente artigo se propõe a explorar perspectivas quanto ao uso dessas metodologias ativas diante do cenário cultural atual, refletindo sobre cultura, cada dia mais também digital, e sobre as relações feitas entre os termos 'metodologias ativas' e 'aprendizagem ativa', a partir do questionamento sobre a sua relevância pedagógica e as discussões existentes entre as metodologias e o momento social/cultural em que se vive. Em reflexão referente a isso, percebe-se o uso dessas metodologias enquanto possibilidade de fornecer um espaço mais atuante para o estudante, que é um ser naturalmente ativo, em sala de aula e trabalhar com diferentes metodologias favorecendo as várias habilidades presentes nos estudantes de uma turma.
\end{abstract}

Palavras-chave: Metodologias ativas. Cultura digital. Ensino.

\begin{abstract}
Faced with the current challenges of education in the context of digital culture and information society, it is important to think about the methodological approaches used in the classroom in order to provide an opportunity for the formation of a student active in this social and cultural context. In this sense, the active methodologies demonstrate work possibilities where the student can have autonomous, creative and exploitative learning action strengthened by the support of the teacher as a mediator and questioner. This article aims to explore perspectives on the use of these active methodologies in the current cultural scenario, reflecting on culture, increasingly digital as well, and on the relationships between the terms 'active methodologies' and 'active learning', based on questioning about its pedagogical relevance and the existing discussions between the methodologies and the social / cultural moment in which
\end{abstract}

\footnotetext{
* Mestranda em Educação em Ciências: Química da vida e saúde pela Universidade Federal do Rio Grande do Sul (UFRGS). Professora de educação básica da rede pública do estado do Rio Grande do Sul, Brasil. Orcid id: orcid.org/0000-0001-9738-6189.E-mail: mai-bcorrea@hotmail.com

** Pedagoga, Mestre e Doutora em Educação pela Faculdade de Educação da Universidade Federal do Rio Grande do Sul (UFRGS). Professora no Departamento de Estudos Especializados na Faculdade de Educação (FACED/UFRGS). Orcid id: orcid.org/0000-0003-1089-3271. E-mail: cintia.boll@ufrgs.br
} 
it lives. Reflecting on this, we can see the use of these methodologies as a possibility to provide a more active space for the student, who is a naturally active being, in the classroom and work with different methodologies favoring the various skills present in the students of a school. class.

Keywords: Active methodologies. Digital culture. Teaching.

\section{Introdução}

O ensino está sempre exposto a uma grande variedade de desafios pois envolve práticas sociais e está estudante a mudanças provocadas pela cultura. Em tempos de cultura digital, de dispositivos móveis, os desafios encontram-se também em acompanhar uma sociedade de conhecimentos baseada nas competências pessoais, sociais e cognitivas, em um contexto em que as informações estão, para alguns, sob mais fácil acesso (independente da qualidade com que se apresentem) e em que outras habilidades diante do movimento veloz que se percebe nas estruturas sociais se fazem necessárias. Assim, difundem-se reflexões e debates no desejo de estabelecer compromisso com aprendizagem significativa e contextualizada por meio da interrelação e problematização de outros conteúdos em conjunto com os conhecimentos já construídos.

A convergência vivenciada atualmente, entre educação e tecnologia, promove mudanças nos modos de agir e de interagir com as informações, bem como, nos modos de expor ideias e compartilhar conhecimentos, o que leva um novo aporte de elementos nessa composição até a aprendizagem. Esse cenário pode contribuir para outros desafios aos processos educativos, apresentando novos significados ou sentidos sociais que vão sendo entrelaçados à educação a partir dessas mudanças, fazendo-nos repensar as propostas de ensino (VALENTE; ALMEIDA; GERALDINI, 2017).

Diante disso, os professores são estimulados a articular, em suas práticas pedagógicas, processos de ensino que motivem e provoquem o engajamento dos estudantes. Nesse contexto, a utilização de metodologias ativas no ensino de Ciências e de Biologia pode se constituir como uma ferramenta para articular essas outras composições onde se movimentam saberes e conteúdos cotidianos ao estudante provocando problematizações nas situações de ensinoaprendizagem e na resolução de situações-problemas. Além disso, é possível descentralizar o ensino apenas da figura do professor e fomentar a participação dos estudantes, pois que são eles os estudantes de construção do próprio aprendizado.

Dessa forma, este artigo tem por objetivo apresentar perspectivas de aplicação e promover a reflexão sobre o uso de metodologias ativas no ensino. Para tanto, é abordada inicialmente uma reflexão diante do contexto atual e de fatores importantes a serem considerados no ensino. Em seguida, é apresentada a conceituação e a base teórica que fundamenta a utilização de metodologias ativas na educação. Posteriormente, é elaborado um contraponto entre metodologia ativa e aprendizagem ativa. Por fim, o artigo relaciona as metodologias ativas em integração com a cultura digital.

\section{Caminhos metodológicos}

$\mathrm{O}$ artigo decorreu de uma pesquisa bibliográfica referente ao tema "Metodologias Ativas" com a motivação de explorar suas perspectivas de uso no ensino de Ciências e de outras áreas do conhecimento através de reflexões diante das relações que essa linha metodológica 
apresenta com o contexto atual de ensino imerso em uma cultura digital. Essa ação inicial foi fundamental, pois que, concordando com Gil (1991), a pesquisa bibliográfica não só permite uma cobertura ampla sobre um tema, possibilitando a síntese e a análise crítica do que já foi produzido na área de interesse, como também, permite estabelecer relações de dados com o problema proposto, por meio de leituras exploratórias, seguidas por leituras seletivas de material. A partir disso, é possível realizar uma leitura analítica e, por fim, uma leitura interpretativa (GIL, 1991).

Para tal, buscou-se, entre os meses de outubro de 2018 e maio de 2019, por artigos científicos nas plataformas "Scielo", "Google Acadêmico" e "Portal de periódicos da Capes" com os seguintes termos: metodologias ativas, metodologias de ensino, aprendizagem ativa, desafios do ensino e cultura digital. Os termos de busca foram usados isoladamente, pois ao encontrar discussões sobre as metodologias ativas a partir de um único termo de busca oportunizou acesso a outros artigos que provocaram novas reflexões. Porém, utilizou-se o termo "metodologias ativas" combinado com "aprendizagem ativa" para a construção da seção 5 e o termo "metodologias ativas" combinado com "cultura digital' para desenvolver as reflexões apresentadas na seção 6 e relacioná-las ao contexto cultural em suas possíveis similaridades e oposições semânticas.

Os artigos encontrados na busca foram selecionados mediante adequação ao tema de cada seção que se pretendia elaborar, onde foram usados artigos datados a partir do ano de 2010 quando o foco se centrava nas metodologias ativas, mas também foram utilizados artigos anteriores a 2010 para a construção de bases teóricas relacionadas ao tema cultura. Vários autores foram encontrados realizando discussões e considerações em torno do uso de metodologias ativas, mas se apresentaram similaridades entre os autores adotados como embasamento para essas produções, dentre os quais citam-se Morán (2015), Valente (2014) e Berbel (2011).

O presente artigo apresenta algumas considerações e discussões sobre metodologias ativas enquanto prática pedagógica a partir de autores que já trabalham com esse tema, demonstrando exemplos dessas metodologias que podem ser usadas em sala de aula, sem o objetivo de, nesse artigo, aprofundar cada um desses exemplos ou possibilidades de aplicação. O foco encontra-se na conceituação do termo "metodologias ativas", sua relevância diante do contexto educacional atual e sua relação com a cultura digital. Além disso, se propõe em estabelecer relações e contrapontos existentes entre o conceito de metodologias ativas e o conceito de aprendizagem ativa, uma vez que esses termos acabam sendo utilizados como sinônimos em algumas situações.

\section{Desafios da educação na contemporaneidade}

Quem trabalha com as séries finais do Ensino Fundamental e com o Ensino Médio sabe que um dos desafios da educação atual está em promover e manter a motivação e o envolvimento dos estudantes nos conhecimentos que se pretende construir. A maior parte dos estudantes hoje está incluída, de uma forma ou de outra, em um mundo tecnológico, onde se movimentam várias possibilidades também de estudos. Além disso, os estudantes do Ensino Fundamental apresentam uma grande energia e inquietude e, para eles, permanecer enquanto ouvinte como única, ou quase única, possibilidade de estudo por quatro horas diárias é, no mínimo, um grande desafio.

Percebemos que a educação está vivendo ainda um impasse diante de tantas mudanças na sociedade, o que provoca questionamentos diante de como propor outras para provocar 
aprendizagens, construir projetos de vida e conviver com os demais. A escola que espera por resultados padronizados ignora que a sociedade do conhecimento é baseada em competências cognitivas, pessoais e que exigem proatividade, colaboração, personalização e visão empreendedora (MORÁN, 2015). Mas não nessa ordem. Ao pensarmos na escola enquanto parte da cultura e movimentada às suas interferências é que se constata que ela existe e vive nesses processos culturais e sociais nunca possíveis de padronizações.

Essa reflexão é percebida por Boll e Kreutz (2010) ao citarem que os novos jeitos de aprender, nos dias de hoje, escapam ao modelo hierárquico, sequencial, linear e fechado em apenas um turno escolar. Compreendem a ideia de rede no ato de conhecer, alterando formas e jeitos de aprendizagem e interpelando-nos a pensar novas formas de escolarização e de fazer cultura. Nesse sentido, Zaluski e Oliveira (2018) refletem que a ação de aprender inclui um processo reconstrutivo que gere possibilidades para estabelecer diferentes formas e tipos de relações entre os fatos e os objetos, de modo a promover ressignificações internas e contribuições para a reconstrução dos conhecimentos, por meio da constituição de novos saberes, visando a uma educação significativa que estimula transformações e rompe os marcos da pedagogia tradicional.

Para se alcançar esses rompimentos conceituais e as ressignificações que promovam uma educação integral Freire (2015) ratifica que a ação professor é a base de uma boa formação e que ela contribui para a construção de uma sociedade pensante. Porém, segundo Debald (2003), em muitos casos se percebe que a dificuldade não está na ação professor ou no conteúdo em si, mas no aspecto metodológico, ou seja, na abordagem prática, no recurso que se apresenta imbricado à ação do professor e ao conteúdo.

\section{Embasamento para o uso de metodologias ativas}

Considerando o ensino como a troca constante de saberes que visem a (re) construção de conhecimentos entre professor e estudante, que não se reduz a visão simplista da transmissão vertical de conceitos imutáveis, o trabalho com as metodologias ativas evidencia um caminho de potencial conquista de autonomia pelos estudantes. Evidencia o que de uma forma ou outra sempre se soube.

É possível dizer que a abordagem em torno das metodologias ativas se apresenta a partir do movimento escolanovista, vivenciado entre o final do século XIX e o início do século XX, através da reflexão sobre a teoria e a prática na perspectiva de superar as noções mais tradicionais de ensino. As discussões acerca dessas potencialidades em torno das metodologias ativas decorrem de propostas pedagógicas desenvolvidas por teóricos como Paulo Freire, John Dewey e Carl Rogers, que compreendem que cada indivíduo possui seu ritmo próprio de aprender e que esse aprender ocorre baseado em situações contextualizadas e significativas. Dewey, por exemplo, entendia que a educação e a vida dos estudantes são coisas indissociáveis. Com base nisso, seus trabalhos prezavam pela experimentação sobre as distintas realidades dos estudantes. Freire corrobora muitas das noções apresentadas por Dewey, sendo que sempre valorizou um aprendizado contextualizado, em que a vivência do estudante constitua o embasamento para os seus processos de aprendizado, assim como, apresentou reflexões sobre os princípios da ação-reflexão-ação. Rogers, por sua vez, acreditava num processo constante de atualização onde os aprendizados acontecem para atingir essa atualização sendo a escola, através do professor, um meio para facilitar esse processo (ARAÚJO, 2015).

É possível perceber que as noções em torno das metodologias ativas não são eminentemente novas, pois estão presentes de uma forma ou outra, ao menos, há um século nos 
debates educacionais, ainda que não fosse usada essa denominação especificamente. Além disso, ao pensarmos na estrutura de aplicação dessas metodologias, que incluem o aprendizado cooperativo, ou seja, a intenção de um estudante protagonista, crítico e reflexivo em relação com o outro, também podemos perceber que essas reflexões se fazem presente nas discussões sobre as metodologias usadas pelos professores, sejam em trabalhos de grupo, em exposições orais, em questões mais reflexivas, em atividades lúdicas etc. O ponto essencial, pode-se dizer, é que nas últimas décadas parece ter se evidenciado que uma escola não consiga atender aos desejos de aprender em tempos de mudanças sociais, culturais e tecnológicas tão próximas às vidas cotidianas de seus estudantes. Assim, parece-nos que quanto maior se apresentam em tempos de cultura digital os movimentos sociais, mais aparente é o distanciamento entre o que se espera de um estudante e os modos como a escola trabalha para alcançar esse objetivo. É diante disso que surgem novas formas de dizer o mesmo, bem como, novas nomenclaturas que parecem atrair a comunidade pedagógica sobre "novas" formas de pensar a educação ainda que boa parte dessa novidade esteja nos termos usados... Valente, Almeida e Geraldini (2017) refletem acerca disso, quando expõe que,

\begin{abstract}
A tentativa de envolver os aprendizes, de modo que possam ser mais ativos no processo de aprendizagem, não é nova. Por exemplo, Anastasiou e Alves (2004) descrevem cerca de 20 estratégias de "ensinagem" que preveem a participação ativa dos estudantes, como, por exemplo, aula expositiva dialogada, criação de portfólios, elaboração de mapas conceituais etc. Esses autores não mencionam o uso das TDIC no desenvolvimento dessas metodologias, embora isso possa acontecer com praticamente todas elas. Assim, é preciso ampliar os horizontes quanto ao uso das metodologias ativas por meio das tecnologias digitais e não se ater ao que está em “moda" na atualidade (VALENTE; ALMEIDA, GERALDINI, 2017, p. 565-466).
\end{abstract}

Outros autores seguem conceituando e discutindo a utilização de metodologias de ensino denominadas ativas na tentativa de propor uma convergência mais eficaz entre a sociedade e a educação, de forma contextualizada e na intenção de desenvolver uma aprendizagem mais significativa. Apresentamos o quadro abaixo no desejo de sucintamente indicar algumas referências que são citadas com frequência em artigos que abordam a temática.

Quadro 1 - Síntese dos autores que refletem e discutem as metodologias ativas.

\begin{tabular}{|l|l|}
\hline \multicolumn{1}{|c|}{ Autores } & Ideias centrais que embasam as discussões sobre metodologias ativas \\
\hline John Dewey (1978) & $\begin{array}{l}\text { Os aspectos ativos (expressão, movimento) precedem os aspectos } \\
\text { passivos (impressão, sensação). Portanto a educação deve partir da } \\
\text { experiência ativa promovendo reflexões sobre ela, e oportunizando esse } \\
\text { processo de reconstrução e reorganização da experiência pelo próprio } \\
\text { aprendiz. }\end{array}$ \\
\hline Berbel (2011) & $\begin{array}{l}\text { Para desenvolver a aprendizagem por meio de experiências reais ou } \\
\text { simuladas deve-se buscar a elaboração de soluções para os próprios } \\
\text { desafios experienciados. }\end{array}$ \\
\hline Valente (2014) & $\begin{array}{l}\text { O foco do processo de ensino é no estudante, envolvendo-o na } \\
\text { aprendizagem por descobertas, investigação, resolução de problemas. }\end{array}$ \\
\hline Morán (2015) & $\begin{array}{l}\text { As metodologias escolhidas devem acompanhar os objetivos de } \\
\text { aprendizagem que se pretende atingir. Para se formar indivíduos mais } \\
\text { proativos é necessário um espaço em que devam ser desafiados a avaliar } \\
\text { informações e tomar decisões, além de fomentar a criatividade em busca } \\
\text { de postura participativa e reflexiva em todas as etapas de seu aprendizado. }\end{array}$ \\
\hline Diesel; Baldez; Martins (2017) & $\begin{array}{l}\text { Evidenciam as convergências entre as metodologias ativas e algumas } \\
\text { correntes teóricas entre elas o interacionismo que relaciona fortemente }\end{array}$ \\
\hline
\end{tabular}




\begin{tabular}{|c|c|}
\hline Autores & Ideias centrais que embasam as discussões sobre metodologias ativas \\
\hline & $\begin{array}{l}\text { elementos do ambiente e interações sociais na construção do aprendizado } \\
\text { ativo. Indicam também a pedagogia de Dewey pela perspectiva de uma } \\
\text { contínua reconstrução de experiências e a Freiriana pela ação-reflexão- } \\
\text { ação que foca nos espaços para discussões, argumentação e contrapontos. }\end{array}$ \\
\hline $\begin{array}{l}\text { Valente; Almeida; } \quad \text { Geraldini } \\
(2017)\end{array}$ & $\begin{array}{l}\text { Apresentam a importância de se criar situações práticas em que os } \\
\text { estudantes precisem acessar os conhecimentos teóricos, pensar sobre a } \\
\text { ação a ser tomada, reelaborar aprendizados durante as atividades } \\
\text { desenvolvendo criatividade. }\end{array}$ \\
\hline
\end{tabular}

Fonte: CORRÊA; BOLL, 2019.

As metodologias ativas se apresentam, portanto, como desejo de criar possibilidades de aprender especialmente a partir de um papel mais ativo nessa construção enquanto crítica e reflexão. Borges e Alencar (2014) indicam ser possível entender as metodologias ativas como meios utilizados em sala de aula pensados para o desenvolvimento do aprendizado em que se buscam formação crítica em tempos de cidadãos do mundo. Esses meios estariam centrados em formas de favorecer a autonomia desses estudantes, e isso poderia ser trabalhado através do desenvolvimento à curiosidade, de momentos em que se exige a tomada de decisões sejam elas individuais ou coletivas.

Portanto, as metodologias ativas abrangem várias formas de trabalhar com as temáticas e os conhecimentos, não se tratando de um modelo único e estático, mas sim formas de abordagens em que se prevê o estudante enquanto agente de seu aprendizado que se envolve ativamente nesse processo:

O estudante deve ler, escrever, perguntar, discutir ou estar ocupado em resolver problemas; bem como, realizar tarefas mentais de alto nível, como análise, síntese e avaliação. Sendo assim, a aprendizagem ativa deve promover atividades que ocupam o estudante em fazer alguma coisa e, ao mesmo tempo, o leva a pensar sobre as coisas que está fazendo (SILBERMAN , $1996^{1}$ apud BARBOSA; MOURA, 2013, p. 55).

A metodologia ativa é, portanto, uma concepção educativa que estimula processos construtivos de ação-reflexão-ação (já abordados por Freire), em que o estudante tem uma postura ativa em relação ao seu aprendizado numa situação prática de experiências, por meio de problemas que lhe sejam desafiantes e lhe permitam pesquisar e descobrir soluções (GEMIGNANI, 2012). Autores como Saviani (2009) e Libâneo (2009), entretanto, discutem e alertam para que as metodologias não sejam supervalorizadas, indicando que se faz necessário propor tecnologias acessíveis e realizar abordagens críticas na seleção de conteúdo, o que encontra convergência com o exposto por Freire e Dewey (LIMA, 2017).

É possível indicar algumas metodologias que consideram as discussões propostas tais como a Aprendizagem Baseada em Projetos (ABP), que visa a construção do conhecimento através da investigação propondo soluções para problemas (BERBEL, 1999 apud MORÁN, 2015, SOUZA; DOURADO, 2015), o Peer Instruction (PI) que foca a interação e o debate entre grupos para a resolução de atividades ou exercícios que abordem um conteúdo específico (MAZUR, 2015), a Rotação por Estações (RE), que propõe dispor atividades em estações (mesas ou bancadas) de forma simultânea, abordando temas distintos que se inter-relacionam

\footnotetext{
${ }^{1}$ SILBERMAN, Melvin. Active learning: 101 strategies do teach any subject. Massachusetts: Ed. Allyn and Bacon, 1996.
} 
uns aos outros (MORÁN, 2015), a Sala de Aula Invertida (SAI), que consiste na leitura e no estudo de um conteúdo pelos estudantes antes de iniciá-los em sala de aula, provocando o estabelecimento de observações e dúvidas para que, durante a aula, essas questões sejam explanadas (VALENTE, 2014), a Gamificação, que encontra relevância no fato de que, atualmente, é possível propor muitas aprendizagens advindas das interações com os games e o Science, Technology, Engineering and Mathematics (STEM, Ciência, Tecnologia, Engenharia e Matemática, em português) que propõe a criação de projetos que associam as disciplinas com atividades práticas e divertidas para que os estudantes participem de resolução de problemas reais aprendendo a planejar ações exercitando a colaboração e a ressignificação do erro em equipe (PUGLIESE, 2017; SILVA, 2017).

A rotação por estações é uma aplicação metodológica que está também presente no ensino híbrido que se constitui por apresentar uma parte do ensino online, em uso da cultura digital e com algum controle sobre o tempo, e o modo do estudo mais presencial (CHRISTENSEN; HORN; STAKER, 2013). Entretanto, Morán (2015) agrega à abordagem outra dimensão, a da metodologia ativa, uma vez que também favorece o aprendizado personalizado exigindo do estudante uma postura mais autônoma e independente em certos momentos.

Ao pensar na abordagem STEM, por sua vez, Pugliese (2017) expõe, apoiado em autores como Becker; Park (2011), Kelley; Knowles (2016), Gamse et al. (2017), que pode ser encarado de quatro formas distintas: enquanto metodologia, enquanto currículo, enquanto política pública e enquanto modelo educacional. Como metodologia essa abordagem ocorreria no modo hands on baseado em solução de problemas, envolvendo a pesquisa, o levantamento de hipóteses e a construção de protótipos, exigindo a ação ativa e protagonista do estudante no desenvolvimento de sua autonomia. Silva (2017) reforça esse sentido do STEM enquanto uma metodologia ativa que provoca a autonomia e a criatividade do estudante na busca pelo desenvolvimento de uma aprendizagem mais significativa.

As abordagens pedagógicas aqui discutidas apresentam seu foco no protagonismo do estudante enquanto (re) construtor ininterrupto de seu próprio aprendizado. A partir de questionamentos, confrontos, pesquisas, trocas, projetos e infinitas outras possibilidades o estudante cria o seu espaço, o seu caminho de ação e expressão de forma mais visivelmente ativa do que em metodologias de ensino mais tradicionais que visualmente provocam padronizações. Essa concepção de trabalho pedagógico compreende as reflexões expressas pela teoria sociointeracionista, que acredita em um aprendizado através de diferentes interações (com os pares, com o ambiente, com os recursos, com o professor etc) em direção à construção de uma educação mais dinâmica e colaborativa.

Paiva et. al, por exemplo, realizaram em 2016 uma revisão integrativa sobre 10 artigos que tratassem do tema "Metodologias ativas" e concluíram que "não existe consenso absoluto sobre as formas de operacionalização dessas metodologias, elas constituem bases teóricocríticas congruentes, mas não absolutas" (PAIVA et al; 2019, p.151). Além disso, apresentaram as metodologias ativas como alternativas que expõem os estudantes à problemas que mobilizam seus conhecimentos a fim de compreendê-los e resolvê-los. Neste estudo são apresentados o desenvolvimento da autonomia do estudante, o trabalho em equipe, o rompimento com as metodologias tradicionais, a integração entre teoria e prática como ações que contribuem para o desenvolvimento da autonomia enquanto possibilidade de não só explorar a criatividade, mas especialmente a reflexão e a ação.

As metodologias ativas de ensino abordam a abertura de espaço escolar em direção à outras possibilidades de ação e atuação crítica. É nessa perspectiva que as metodologias ativas 
se mostram como grandes aliadas do processo de ensino-aprendizagem, permitindo que o estudante explicite seus próprios caminhos de construção do conhecimento, identificando erros e desenvolvendo a capacidade de traçar novas possibilidades que lhe proporcionem o resultado esperado.

Esse processo de acerto e erro reconhecido como uma reflexão sobre o caminho que está se tomando é uma atitude de grande valia, pois permite que o estudante construa a sua autonomia em sua caminhada e crie novas possibilidades. Dessa forma, o erro é encarado como parte do processo e não como falha que bloqueia o aprendizado.

Essa percepção é explorada em Pozo; Crespo (2009), ao afirmarem que,

Em uma sociedade que, cada vez mais, exige dos estudantes e futuros cidadãos que usem seus conhecimentos de modo flexível diante das tarefas e demandas novas, a partir dos conhecimentos adquiridos e que vinculem seus conhecimentos escolares com a sociedade da informação na qual estão imersos, não basta encher a cabeça dos estudantes: é preciso ensiná-los a enfrentar os problemas de um modo mais ativo e autônomo, o que requer não só novas atitudes, contrárias às geradas por um modelo tradicional baseado em um saber externo e autoritário, mas sobretudo destrezas e estratégias para ativar adequadamente os conhecimentos (POZO; CRESPO, 2009, p. 251).

É nessa perspectiva que se situam as metodologias ativas: como uma possibilidade de entrecruzamento processual que fortalece a perspectiva do professor (ensino) e do estudante (aprendizagem), ideia corroborada por Freire (2015) ao se referir à educação como um processo que não é realizado por outrem, ou pelo próprio estudante, mas que se realiza na interação entre indivíduos históricos por meio de suas palavras, ações e reflexões (DIESEL; BALDEZ; MARTINS, 2017).

Nesse processo de centralizar o estudante na construção do próprio aprendizado, Woods (1994 apud Lovato, et al, 2018) indica alguns itens a serem observados,

a) explorar o problema, levantar hipóteses, identificar e elaborar as questões de investigação; b) tentar solucionar o problema com o que se sabe; c) identificar o que não se sabe e o que é preciso saber para solucionar o problema; d) priorizar as necessidades de aprendizagem, estabelecer metas e objetivos de aprendizagem e alocar recursos de modo, a saber, o que, quanto e quando é esperado e, para a equipe, determinar as tarefas individuais; e) planejar, delegar responsabilidades para o estudo autônomo da equipe; f) compartilhar o novo conhecimento para que todos os membros aprendam os conhecimentos pesquisados pela equipe; f) aplicar o conhecimento para solucionar o problema; e g) avaliar o novo conhecimento, a solução do problema e a eficácia do processo utilizado, refletindo sobre o processo (WOODS, 1994 apud LOVATO et. al, 2018, p. 158).

Os itens citados por Woods apud Lovato et al. (2018) revelam posturas atitudinais importantes para a atuação cidadã e profissional, evidenciando um ganho não apenas para a vida acadêmica do estudante, mas para sua vida em sociedade. Além disso, esses desafios que se apresentam aos estudantes tendem a desenvolver sua capacidade de aprendizado, o que se mostra importante tanto nas disciplinas escolares quanto nas não escolares.

Além disso, ao propor as metodologias ativas de ensino-aprendizagem na prática professor, a tendência é de que ele fique mais atento à reflexão sobre sua prática, mais dialógico 
com os estudantes e com os conteúdos e competente para agir sobre o planejamento educacional considerando a elaboração de espaços de aprendizagens significativas, assim como, a promoção de intervenções em problemas demandados pelos ambientes de aprendizagem (GEMIGNANI, 2012). As metodologias ativas se revelam como um considerável recurso para fortalecer o processo de ensino e de aprendizagem de uma forma significativa estabelecendo formas de interação que favorecem a motivação autônoma através da valorização da percepção do estudante de ser ele o mentor de sua própria ação (ZALUSKI; OLIVEIRA, 2018).

Dessa forma, é importante pensar sobre a temática das metodologias ativas de uma forma contextualizada historicamente e, também, crítica, de modo a reconhecer as longínquas raízes dos princípios envolvendo o estudante como protagonista de seu aprendizado, que deve agir e refletir sobre tal, assim como, elaborar soluções baseadas em conhecimentos para superar desafios e dificuldades que vão surgindo. E, a partir disso, refletir sobre a escola que se tem neste século XXI e os estudantes que se pretendem formar através dela, buscando formas de aliar essas duas visões e utilizar esses princípios como possibilidade de atingir esses novos desejos e necessidades requeridas pela sociedade moderna, independente dos títulos modernizados que surjam para defini-los. Se os novos termos podem atrair os indivíduos para conhecer as ideias que eles apresentam, que isso possa ser explorado para incutir a carga histórica e também as reflexões sobre os novos modos de aprender e ensinar, na busca por essas aprendizagens contextualizadas e significativas.

Por fim, faz-se importante pensar em dois pontos. Um deles trata da postura do estudante que poderá apresentar resistência ou dificuldade em elaborar suas próprias criações, pois que vinculado à metodologias que não exigiam dele tanta atividade, tanta ação em direção à busca pela responsabilidade de sua própria aprendizagem. O outro ponto trata de não supervalorizar uma teoria apenas por ela aparentar a "novidade" como fator de solução às mazelas do ensino de forma isolada, tal qual reflete Vázquez ${ }^{2}$ (1977) através do exposto por Berbel (2011, p.37), ao dizer que "A teoria em si [...] não transforma o mundo. Pode contribuir para sua transformação, mas para isso tem que sair de si mesma, e, em primeiro lugar, tem que ser assimilada pelos que vão ocasionar, com seus atos reais, efetivos, tal transformação"

\section{Metodologias ativas ou aprendizagem ativa?}

Os termos 'metodologias ativas' e 'aprendizagem ativa', pela semelhança, podem levar a uma ideia de que ambas as terminologias designam a mesma coisa. Entretanto, é importante compreender o significado dos termos e dos contextos em que os mesmos são utilizados para que seja possível fazer uma correta interpretação do que está sendo abordado. Para isso, buscarse-á o auxílio da semântica e da etimologia.

Quando o assunto é metodologia, no contexto pedagógico, pensa-se em aplicação de diferentes métodos no processo de ensino-aprendizagem. A palavra metodologia é de origem grega methodos, onde metho significa "meta ou objetivo" e hodos indica "um caminho", ao passo que o sufixo logia significa "estudo". Tem-se, então, metodologia como o estudo dos caminhos que serão percorridos a fim de se alcançar alguma meta ou algum objetivo.

Vale lembrar que existem várias metodologias de ensino, algumas mais tradicionais, outras mais construtivistas, uma vez que cada professor ou instituição de ensino pode ter uma compreensão distinta dos melhores métodos a serem adotados para o ensino de algum componente escolar; assim como, vale lembrar também que a escolha por uma metodologia

\footnotetext{
${ }^{2}$ SÁNCHEZ VÁZQUEZ, Adolfo. Filosofia da práxis. 4. ed. Rio de Janeiro: Paz e Terra, 1977.
} 
está amparada em orientações filosóficas (de homem, de mundo, de sociedade), movimentando as ações assumidas durante a aula e as metas de ensino almejadas, ainda que, não estejam expressas claramente sobre seu fazer pedagógico (ARAUJO, 2015).

Essa reflexão é percebida por Araújo (2015) ao apresentar que,

\begin{abstract}
Insere-se a metodologia de ensino em um dado contexto, e se operacionaliza através da aula, pela qual se revela singular, mas sem perder de vista o mundo social e o cotidiano da instituição escolar, bem como a totalidade social (...). Portanto, a metodologia de ensino não é restrita à aula ou à sua preparação ou mesmo ao seu planejamento; pelo contrário, ela se plenifica através das relações com a prática social, a qual lhe confere um caráter de historicidade, de interlocução e de participação. Sob essa orientação, não haveria uma metodologia de ensino unitária, separada ou desvinculada de concepções epistemológicas (ARAUJO, 2015, p. 4).
\end{abstract}

Nesse sentido, as metodologias ativas seriam estratégias pedagógicas de ensino cuja meta/objetivo está em proporcionar ao estudante um protagonismo escancarado do seu processo de ensino-aprendizagem (CHAQUIME; MILL ${ }^{3}$ apud MILL, 2018). Portanto, o termo 'metodologias' está se referindo a uma forma de trabalhar para alcançar o(s) objetivo(s) estabelecido(s), e o acréscimo do termo 'ativas' é utilizado para especificar que esse método prevê claramente um papel ativo e interativo do estudante durante todo esse processo.

Ao passo que ao falar de aprendizagem, estamos falando do ato de aprender, evento natural da vida humana, provocado por estudo, experiências, observação, curiosidade, seja em espaços formais ou informais, com ou sem intencionalidade, tendo ou não a referência de um ambiente físico (BOLL; RAMOS; REAL, 2018). Aprender é inerente à vida humana, aprendemos desde que nascemos e seguiremos a aprender sempre que quisermos ou nos permitirmos a tal. Como a aprendizagem prevê uma ação, ela tende a ser inevitavelmente ativa, uma vez que algo novo é observado, construído ou internalizado, tal como Valente; Almeida e Geraldini analisam,

Independentemente de como se entende a aprendizagem, ela acontece em função da ação do estudante, em interação com o meio. Quer ela se restrinja à memorização de informação, quer seja mais complexa, envolvendo a construção de conhecimento, o aprendiz tem que ser ativo, realizando atividades mentais, para que essa aprendizagem aconteça. Assim, não é possível entender que um indivíduo aprenda alguma coisa sem ser ativo (VALENTE; ALMEIDA; GERALDINI, 2017, p. 464).

Pela compreensão semântica desses dois termos, podemos perceber que eles não tratam de um mesmo conceito e, então, não devem ser usados para um mesmo fim. Ao se falar em Metodologias Ativas, o termo se refere às escolhas pedagógicas que são feitas pelos professores para se alcançar algum objetivo no processo de ensino-aprendizagem. Enquanto, ao se falar em aprendizagem ativa está se referindo a um processo intrínseco dos indivíduos diante do estudo de determinado tema e que, por ser intrínseco e natural ao indivíduo, leva a percepção de que falar em aprendizagem ativa se apresenta linguisticamente redundante. Dessa forma, as Metodologias Ativas se colocam como variações das abordagens pedagógicas com a finalidade

\footnotetext{
${ }^{3}$ CHAQUIME, Luciane Penteado; MILL, Daniel. Metodologias ativas. In: MILL, D. (org.). Dicionário crítico de educação e tecnologias e de educação a distância - Campinas, SP: Papirus, 2018.
} 
de que o estudante se perceba e se envolva como um protagonista durante os caminhos que estabelece para a construção de sua atividade, mantendo-se autônomo nessa construção.

Para entender a utilização atual do termo 'Metodologias Ativas' é preciso considerar o contexto em que ele surge e interage. Se pensarmos em aprendizagem enquanto processo, sabemos que ele prevê naturalmente um papel ativo do estudante para construir um novo conhecimento, independente dos meios usados para tal, necessitando de todo um trabalho mental e neurológico para estabelecer redes neurais. Mas, ao pensarmos nesse termo relacionado ao contexto escolar, fica acessível compreender sua utilização enquanto meio de diferenciar essas metodologias do modo usual de trabalho observado nas salas de aulas mais tradicionais. O termo é usado para chamar a atenção para o papel do estudante enquanto centro de um processo que lhe exige uma postura mais ativa e criativa em relação ao papel que ele costuma utilizar frequentemente como agente mais passivo dentro do processo de aprendizagem. Então, o termo 'Metodologias Ativas' se justifica ao ser comparado com as metodologias mais usuais de ensino, devido a uma mudança de perspectivas das figuras envolvidas no processo de aprender e ensinar e isso fica referenciado no termo para ilustrar interpretativamente essa diferença.

Ainda que a aprendizagem se constitua, por si só, como um processo genuinamente ativo, isso não implica que a organização pedagógica das aulas - a metodologia empregada flexibilize o espaço, a ordem ou o silêncio para o real exercício daquilo que é ativo, com vozes, efervescência e ocupação espontânea do espaço. É nesse sentido que se acrescenta o adjetivo 'ativa' à metodologia, indicando um espaço onde o estudante se (re) constrói imerso em vida, em sentidos, em sentimentos expressos e registrados em sua fala, seu espaço, suas dúvidas, seus erros, seus comentários, suas conexões e seus aprendizados.

\section{As metodologias ativas no contexto da cultura digital}

A última década apresentou um cenário de bons ventos pedagógicos em direção à cultura digital em nossa sociedade. Os novos meios de informação e comunicação em conexões e em rede possibilitam outras formas de criar e compartilhar conhecimento. A velocidade com que a informação alcança os quatro cantos do planeta acaba por mantê-la próxima ao espaço escolar e, se não chegar via instituição, ela chega por meio dos estudantes.

A cultura é estrutura social construída ou, como nos faz pensar Baratto; Crespo (2013, p.17), "se a cultura é um reflexo da ação humana, a cultura se constitui de ação do homem, na sociedade; criando formas, objetos, dando vida e significação a tudo o que o cerca, é essa ação humana que permitiu o surgimento do computador e, por conseguinte, o surgimento da cultura digital". Enquanto estrutura social que vê, ouve e sente, a criação das tecnologias é interação constante na busca sempre por novos desafios, novos equipamentos hoje cada dia mais digital (BARATTO; CRESPO, 2013).

Pensando nos processos envolvidos nessa cultura digital Williams ${ }^{4}$ apud Bortolazzo (2016) explana que, sob sua visão, as tecnologias só tomam o espaço que possuem em virtude do significado cultural que lhes foi dado. Nesse sentido é fundamental focar a interação, pois que é ela que molda as nossas ações sobre a tecnologia e não o contrário. Sendo assim, as tecnologias e suas práticas/sociais não estão distanciadas uma vez que as primeiras emergem da própria intenção humana, por meio de interesses e desejos culturais e históricos.

\footnotetext{
${ }^{4}$ WILLIAMS, Raymond. Technology and Cultural Form. $1^{\circ}$ ed. Londres: Shocker Books, 1975.
} 
Isso vai ao encontro ao exposto por Baratto; Crespo (2013) pois que ao refletir sobre a cultura enquanto processos de significação e ressignificação sociais fornece-lhe valores simbólicos tecidos hoje cada dia mais por meio da conectividade digital (HEINSFELD; PISCHETOLA, 2017). Nesse sentido, Heinsfeld; Pischetola (2017) ainda complementam,

\begin{abstract}
Ao se conceituar cultura digital, considera-se a alteração das relações culturais quanto ao entrosamento entre estudantes e mídias de informação e comunicação, surgida da ruptura na forma como a informação era até então concebida, (re)produzida e difundida. Essa metamorfose, como se observa, caminhou na direção da mobilidade e da ubiquidade. A cultura digital está relacionada à comunicação e à conectividade global, ao acesso e à produção de conteúdo de forma veloz, interconectada, autônoma e mediada pelo digital (HEINSFELD; PISCHETOLA, 2017, p.1352).
\end{abstract}

Boll (2013) apoiada nas reflexões de Pierre Lévy ${ }^{5}$, por sua vez, apresenta cultura digital ou ciberespaço, como a inter-relação de práticas e pensamentos de cunho material e intelectual que se desenvolvem por meio das redes e das tecnologias digitais, possibilitadas pela convergência entre a informática e as telecomunicações. Isso faz compor uma espécie de relação simbiótica entre sociedade e cultura se desenvolveu a partir dessa convergência entre informática e telecomunicação, instituindo o que hoje chamamos de cultura digital, ou nos termos de Lévy, ciberespaço.

O contexto de cultura digital em movimento, pois que sempre em cenário de mudança, abre espaço para diversas redes de linguagem e comunicação por meio de fluxos que se oferecem para ancorar o protagonismo escolar que se espera nesses tempos e que se deseja quando a metodologia é ativa. Essa ação-reação pode criar o que Boll (2013) denomina de espect-autor, pois além de atuar sobre essas redes os criadores assumem visivelmente as posições de autoria e de criação. Dessa forma, a construção dos conhecimentos é singular mas não individual, uma vez que os processos de produção de sentido se estabelecem na relação do criador consigo mesmo mas também na relação com outros criadores e contextos, em uma verdadeira aparição entre diversos mundos (RAMOS; BOLL, 2019).

É interessante observar, portanto, o perfil desses jovens que ocupam e transformam a escola atualmente em tempos de cultura digital e metodologias ativas. São "multivíduos" (CANEVACCI, 2008) conectados e coletivos, com suas linguagens e com habilidades que consomem e, ao consumir, também criam e compartilham recursos pelas tecnologias cada dia mais móveis: são vídeos, vlogs, memes, textos... em aplicativos cada dia mais customizados ${ }^{6}$ (BOLL, 2013). Sobre esse novo perfil juvenil que aprende e também ensina:

\begin{abstract}
Entretém-se e aprendem convivendo em vários contextos de aprendizagem, com variados espectadores na esfera pública digital. Estabelecem trajetórias pessoais de aprendizagem por meio dos aplicativos fixos ou móveis ou recursos físicos para aprofundar os seus conhecimentos ou mesmo para buscas rápidas de conteúdo. Esses contextos de atividades, sediados em subsistemas, tais como as rodas de conversas, comunidades de aprendizagem, redes de games, oportunizam distintos processos comunicacionais de forma intermitente (RAMOS; BOLL, 2019, p. 58-59).
\end{abstract}

\footnotetext{
${ }^{5}$ LÉVY, Pierre. Cibercultura. São Paulo. Editora 34. 1999.

6 Multivíduo é um conceito criado pelo Antropólogo Visual, professor da Universidade de Roma, Massimo Canevacci (2008) para se referir à variedade de "eus" múltiplos, em contraponto à ideia de indivíduos. Multivíduos cada dia mais conectivos, convivendo em tempos de metrópoles comunicacionais, plurais, fluidos, ubíquos, múltiplos em suas vozes, olhares e desejos de pertencimentos.
} 
É possível crer que os fluxos de comunicação em tempos de cultura digital e metodologias ativas na educação têm se mostrado muito mais interativos e colaborativos, sempre com alguma incorporação e/ou manifestação em uma estética digital. Isso tem proposto movimentar a educação para outros espaços e plataformas muito além do espaço escolar: ela se entremeia com a vida dos estudantes e segue presente em suas leituras, pesquisas, questionamentos... Essa compreensão é cada dia mais problematizada em sala de aula pelos professores mais atentos aos movimentos, especialmente aqueles que incluem em sua busca metodologias mais ativas e conectivas, que valorizam a pluralidade e complexidade dessas vozes que teimam em se fazer escutar (BOLL, 2019).

Nesse contexto de tecnologias de informação e de comunicação em expansão, não há possibilidades de que o espaço escolar possa escolher se manter alheio a uma estrutura social que já se encontra implementada ao cotidiano da maioria dos estudantes. E essa realidade apresenta, além do desafio de atualização dos professores quanto aos novos jeitos de se trabalhar com indivíduos familiarizados com as mídias e as tecnologias, a necessidade de que essas crianças e esses jovens que se encontram inseridos em uma cultura digital possam utilizar esses meios de modo proveitoso e respeitoso, usufruindo de todos os benefícios e facilidades que essas ferramentas podem promover com a consciência ética de seu uso.

As formas de aprender e ensinar, conforme Pozo; Crespo (2009), são uma parte intrínseca da cultura e, portanto, sofrem as modificações dessa cultura. Em decorrência disso, surge um anseio formativo em promover a interiorização e assimilação da cultura em que estamos inseridos, a fim de desenvolver capacidades de acesso e de renovação dos produtos culturais. Para esses autores,

\footnotetext{
Cada revolução cultural nas tecnologias de informação e, como consequência disso, na organização e na distribuição social do saber trouxe consigo uma revolução paralela na cultura da aprendizagem, a mais recente das quais ainda não terminou: as novas tecnologias da informação, unidas a outras mudanças sociais e culturais, estão abrindo espaço para uma nova cultura da aprendizagem, que transcende o marco da cultura impressa e deve condicionar os fins sociais da educação e, especialmente, as metas dos anos finais do ensino fundamental e médio (POZO; CRESPO, 2009, p. 23).
}

Se, cada vez mais cedo as crianças entram em contato com o mundo digital, mais cedo essas crianças precisam ser orientadas sobre as limitações de seu uso. Muitas vezes, os estudantes têm grande facilidade para acessar jogos, redes sociais ou páginas da internet, mas não possuem habilidades importantes como a síntese e a interpretação da enxurrada de informações que rapidamente se apresenta diante dos olhos, ou não conseguem compreender a gigantesca possibilidade de múltiplos aprendizados que essas ferramentas lhes possibilitam. Nesse sentido, Pozo; Crespo (2009, p. 25) refletem que "os estudantes precisam não tanto mais de informação (embora possam precisar também disso), mas sobretudo [...] como futuros cidadãos vão precisar da capacidade para buscar, selecionar e interpretar a informação". Em contraponto, a escola, como já mencionado, anteriormente neste artigo, encontra o desafio de acompanhar mudanças sociais, culturais e históricas, bem como, as necessidades que surgem a partir disso para uma geração inserida em um contexto digital e promover aprendizagens significativas diante da vida cotidiana desses estudantes, compreendendo a existência de múltiplos espaços de aprendizado, online e offline, individualizado ou em rede. 
Perante essa perspectiva, as tecnologias digitais se apresentam como possibilidades pedagógicas de inserção no contexto de vida dos estudantes como um meio aliado para a promoção dessa aprendizagem significativa a que os professores e instituições têm apresentado a preocupação de desenvolver. Melo; Boll (2014) fazem uma reflexão em torno dessa realidade,

Com a Cultura Digital chegando às escolas brasileiras através de programas governamentais, pesquisas, estudos e discussões sobre novas possibilidades educativas ampliam os espaços de convergências midiáticas para esse fim pois que a base propulsora da aprendizagem escolar se apresenta agora em toda uma comunidade. Uma comunidade que cria redes de comunicação entre a sala de aula e todo o território digital disponível para o acesso (MELO; BOLL, 2014, p. 2).

Boll (2014) reflete, porém, que a cultura digital envolve em si um componente estético onde as redes comunicativas ocupam e transformam os espaços, promovendo interconexões e inteligência coletiva. Sendo assim, esse aspecto deve ser considerado nas intencionalidades pedagógicas no uso das tecnologias e dispositivos midiáticos, num sentido de que se promovam espaços para as manifestações estéticas dos estudantes e dos professores. E, assim, a autora coloca que "a dinâmica da sociedade hoje quer e precisa de uma escola ativa e criadora que apresente atividades tanto de campo de iniciação científica quanto de campo de iniciação artístico-cultural” (BOLL, 2014, p. 219)

As metodologias ativas visam, portanto, conectar a autonomia do estudante à construção de seu conhecimento por meio da pesquisa, interpretação e reflexão de informações e tem o contexto de cultura digital como espaço de reflexão e criação dessas habilidades, de local para exercer ativamente e conectadamente seu papel de autoria e não de espectador. A cultura digital e as metodologias ativas cada dia mais conectivas têm apresentado a sua potência criadora nesses novos tempos. Portanto, como expressa Heinsfeld; Pischetola (2017, p. 1356) a utilização das tecnologias em sala de aula "não se limitaria à utilização da mídia como recurso didático, mas, sim, como viabilizadora da problematização das narrativas que dão sentidos à cultura vigente".

A tecnologia se apresenta cada dia mais como espaço das leituras, das escritas, das criações apesar de apenas oferecer informações e não conhecimentos. Bem, é sabido que ter acesso à informação disponível na cultura digital não significa ter acesso ao conhecimento, uma vez que o segundo depende de uma ação compreensiva e interpretativa sobre a primeira. E é nessa perspectiva que a ação crítica e reflexiva da ação pedagógica pode ativar desejos e sentidos de adesão à ações compreensivas e interpretativas em tempos de cultura digital, quando muito mais que duas formas de apresentar um mesmo conteúdo se exibe mundialmente e em rede.

Almeida (2008) nos revela que ao inserir as tecnologias no cotidiano escolar o professor provoca mudanças no ambiente e nos processos de aprendizado e, essas mudanças precisam ser conscientes da atuação de coautoria de um típico professor mediador junto do estudante. Desse modo, reflete que sobre o uso de tecnologias num sentido de "potencializar práticas pedagógicas que propiciem a autonomia do estudante na busca e geração de informações significativas para compreender o mundo e atuar em sua reconstrução, no desenvolvimento do pensamento crítico e auto-reflexivo do estudante" (PETRIS, 2016, p.22).

Essas reflexões e debates sobre o uso das tecnologias em sala de aula como aliadas dos processos de aprendizagem não são recentes, tal qual a presença da tecnologia em nossas vidas também não o é, mas o contexto em que estamos inseridos é de ampliação e expansão, de um 
movimento constante, porém, já enraizado em nossa cultura. Boll; Kreutz (2009), na escrita do Livro intitulado Cultura Digital: quando a tecnologia se enreda aos usos e fazeres do nosso dia a dia, parte da série "Mais educação" apresentam ao centro dessas reflexões dois pontos importantes: a necessidade de fornecer condições de acesso ininterrupto à internet nos espaços escolares e sociais e a importância de que os professores se introduzam nesse contexto cultural e o (re) signifiquem enquanto ricas possibilidades de aprendizado e fazer pedagógico. Tais colocações são de grande valia quando se quer falar sobre qualidade de ensino e sobre uma escola situada no século XXI, mas que ainda se mostra estruturada em moldes do início do século XX, visto o que nos falam Pozo; Crespo $(2009$, p. 21) "a nova cultura de aprendizagem que se abre nesse horizonte do século XXI é dificilmente compatível com formatos escolares e metas educacionais que praticamente não mudaram desde que as instituições escolares foram constituídas no século XIX”.

As novas gerações de professores, em sua maioria, reconhecem a relação positiva dos avanços tecnológicos como aliados dentro e fora da sala de aula, ainda que encontrem dificuldades com os recursos tecnológicos disponíveis nas escolas e com o tempo para o planejamento dessas aulas. É sob essa ótica e, pensando nas habilidades que podem ser trabalhadas por meio de um aporte tecnológico, mesmo em um contexto onde as tecnologias são limitadas, que o uso de metodologias ativas se constituiu como um suporte pedagógico interessante, indicando espaços de interação e conhecimento em redes (digitais ou não), bem como, aquele papel de explorador/criador que um estudante pode ter diante de uma tela digital.

\section{Considerações finais}

A partir das vivências das autoras proporcionadas em sala de aula no trabalho pedagógico com a educação é possível perceber mudanças no perfil do atual estudante sobre as quais pesquisamos para compor este artigo. Segundo os atuais dados apontados pelo CGI (Comitê Gestor da Internet no Brasil) que estimam "cerca de oito em cada dez crianças e jovens (85\%) com idades entre 9 e 17 anos eram usuários de Internet em 2017”, é possível visibilizar os hábitos pedagógicos em tempos de cultura digital. Temos como apontar clara e rapidamente pelo menos uma ação nos últimos minutos em que estivemos envolvidos em sala de aula para corroborar tal estimativa ao mesmo tempo em que apontamos os professores que, mesmo sabendo da importância da metodologia ativa em sala de aula, não usam a cultura digital para esse fim: são eles os usuários dos celulares para compor suas aulas, mas não para entrar nelas.

Para entrar nas aulas garantindo uma metodologia ativa em seus planos os professores poderiam entrecruzar sua prática pedagógica de modo a promover criticamente o uso da cultura digital em consonância com as concepções de educação que possui. Portanto, faz-se necessário apresentá-las à reflexão como uma possibilidade de ressignificação da prática do professor (DIESEL; BALDEZ; MARTINS, 2017). Nesse sentido, Boll e Axt (2011) refletem que atualmente nos encontramos em tempos de convergência tecnológica, cultural e social e isso se apresenta como um convite para que os professores pensem e (re) construam o fazer professor de acordo com a realidade a que todos estão inseridos. A elaboração de novas tentativas e aplicações metodológicas em sala de aula enriquece o ato pedagógico podendo contribuir com uma formação mais integral dos indivíduos.

$\mathrm{Na}$ perspectiva de enriquecer o pensar e o fazer pedagógico nesses tempos em que vivemos inseridos em uma cultura digital que favorece e valoriza o conhecimento em rede, nota-se que o principal objetivo envolvido na utilização de metodologias ativas está em propor um aprendizado mais autônomo e participativo, considerando situações-problemas e possibilidades mentais em criar respostas ou soluções para elas, exigindo uma conexão de ideias 
que pode ser alcançada por meio da reflexão a partir das leituras dispostas na própria cultura digital, leituras oferecidas amplamente em textos, sons e imagens. Enquanto habilidades importantes em uma formação cidadã essa ação transcende o espaço da escola. Nesse sentido, Morán (2015) reflete que se desejando estudantes mais proativos é necessário que estes sejam desafiados a se envolver nos seus processos de aprendizagem bem como se desejando estudantes mais criativos é notório propor mais espaços para manifestação de sua criatividade, o que se pode experimentar em momentos pedagógicos diferenciados.

As metodologias ativas surgem, então, como a possibilidade de engajar estudantes no ritmo e na construção de sua aprendizagem em tempos especialmente de cultura digital e mídias móveis. Contudo, sabe-se que entrecruzar um tipo de proposta metodológica mais tradicional com outra mais conectiva e ativa pode compor momentos ricos de desafios à participação dos estudantes. A variedade de metodologias durante as aulas atrai os estudantes, motiva-os a se envolver com o que está sendo proposto. Esse interesse em participar de uma aula "diferente" já coloca esse estudante em contato com o tema ou conteúdo que estará sendo abordado e, através desse contato, a possibilidade da construção significativa do aprendizado se expande.

No sentido de fortalecimento das expressões criadoras que constituem potencialidades múltiplas de aprendizagens desse estudante aprendente permanente em vários espaços em tempos de cultura digital e mídias móveis, as concepções de metodologias ativas que consideram as experiências e os processos de (re) construção e auto (trans) formação trilhados por eles produzem sentidos nesses novos espaços também dialógicos do aprender. Essa "possibilidade dialógica (multidirecional) [...] conecta entre si todas as vozes participantes, impelindo-as a produzir sentidos em variação, ampliando horizontes de compreensão e de possibilidades dialógicas no encontro com o outro" (BOLL; AXT; MULLER, 2019, p. 230). Um outro em que todos, professores e estudantes, temos o desejo de pertencer com a nossa voz.

\section{Referências}

ALMEIDA, Maria Elizabeth Bianconcini de. Tecnologia na escola: criação de redes de conhecimentos. 2008.

ARAUJO, José Carlos Souza. Fundamentos da metodologia de ensino ativa. In: Reunião Nacional da ANPEd, 37, 2015, Florianópolis. Anais [...] Florianópolis: Universidade Federal de Santa Catariana, 2015. Disponível em: http://www.anped.org.br/sites/default/files/trabalhogt02-4216.pdf Acesso em 29 mar 2019.

BARATTO, Silvana Simão; CRESPO, Luís Fernando. Cultura digital ou cibercultura: definições e elementos constituintes da cultura digital, a relação com aspectos históricos e educacionais. Revista Científica Eletrônica UNISEB, Ribeirão Preto, v.1, n.2, p. 16-25, ag/dez.2013. Disponível em: http://estacioribeirao.com.br/revistacientifica/arquivos/jul-2.pdf . Acesso em: 14 abr 2019.

BARBOSA, Eduardo Fernandes; MOURA, Dácio Guimarães de. Metodologias ativas de aprendizagem na educação profissional e tecnológica. Boletim Técnico do Senac, Rio de Janeiro, v. 39, n. 2, p. 48-67, maio. 2013.

BERBEL, Neusi Aparecida Navas. As metodologias ativas e a promoção da autonomia de estudantes. Semina: Ciências Sociais e Humanas, Londrina, v. 32, n. 1, p. 25-40, jan./jun. 2011. Disponível em: 
http://www.proiac.uff.br/sites/default/files/documentos/berbel_2011.pdf. Acesso em: 14 mar 2019.

BOLL, Cintia Inês; AXT, Margarete; MULLER, Daniel Nehme. Aplicativos Mobile Pedagógicos para a Educação Básica: da possibilidade dialógica para uma inteligência conectiva. In: Sara Dias-Trindade e Daniel Mill. (Org.). Educação e humanidades digitais: aprendizagens, tecnologias e cibercultura. Coimbra - Portugal: Imprensa da Universidade de Coimbra, 2019, v. 1, p. 207-234.

BOLL, Cintia Inês; RAMOS, Wilsa Maria; REAL, Luciane Corte. Aprendizagem Movel. In: Daniel Mill (Org.) Dicionário crítico de educação e tecnologias e de educação a distância. 1ed. Campinas, SP: Papirus, 2018. 736p.

BOLL, Cintia Inês. Os dispositivos midiáticos na cultura digital: a ousadia enunciada em uma estética que potencializa eu, você e todos os outros que quiserem participar. In: CORÁ, Elsio José. (Org.). Reflexões Acerca da Educação em Tempo Integral. Porto Alegre: Evangraf, 2014, v. 1, p. 211-226.

BOLL, Cintia Inês. A enunciação estética juvenil em vídeos escolares no Youtube. 2013. Tese (Doutorado Educação) - Faculdade de Educação, Programa de Pós-graduação em Educação, Universidade Federal do Rio Grande do Sul, Porto Alegre, 2013. Disponível em: https://www.lume.ufrgs.br/handle/10183/70596 Acesso em 25 abr 2019.

BOLL, Cintia Inês; AXT, Margarete. Fetiches visuais em tempos de convergências tecnológica, mercadológica, cultural e social. CINTED-UFRGS Novas Tecnologias na Educação, Porto Alegre, V.9, n², dezembro, 2011.

BOLL, C. I.; KREUTZ, J. R. A cultura digital: quando a tecnologia se enreda aos usos e fazeres do nosso dia a dia. Brasília, DF: Ministério da Educação. Secretaria de Educação Continuada, Alfabetização e Diversidade, 2010.

BORGES, Tiago Silva; ALENCAR, Gidélia. Metodologias ativas na promoção da formação crítica do estudante: o uso das metodologias ativas como recurso didático na formação crítica do estudante do ensino superior. Cairu em Revista, Salvador, $n^{\circ} 04$, p. 1 19-143. jul./ago. 2014.

BORTOLAZZO, Sandro Faccin. O imperativo da cultura digital: entre novas tecnologias e estudos culturais. Revista Cadernos de Comunicação, Santa Maria, v.20, n.1, art 1, p.1 de 24, jan./abr.2016. Disponível em: https://periodicos.ufsm.br/ccomunicacao/article/view/22133/pdf . Acesso em: 29 mar. 2019.

BZUNECK, José Aloyseo; GUIMARÃES, Sueli Édi Rufini. A promoção da autonomia como estratégia motivacional na escola: uma análise teórica e empírica. In: BERBEL, Neusi Aparecida Navas. As metodologias ativas e a promoção da autonomia de estudantes. Semina: Ciências Sociais e Humanas, Londrina, v. 32, n. 1, p. 25-40, jan./jun. 2011.

CANEVACCI, Massimo. Fetichismos visuais - corpos erópticos e metrópole comunicacional. São Paulo, SP: Ateliê Editorial, 2008. 
CHAQUIME, Luciane Penteado; MILL, Daniel. Metodologias ativas. In: MILL, Daniel. (org.). Dicionário crítico de educação e tecnologias e de educação a distância - Campinas, SP: Papirus, 2018.

CHRISTENSEN, Clayton M., HORN, Michael B., STAKER, Heather. Ensino Híbrido: uma inovação disruptiva? Uma introdução à teoria dos híbridos. Clayton Christensen Institute, 2013.

DEBALD, Blasius Silvano. A docência no ensino superior numa perspectiva construtivista. In: SEMINÁRIO NACIONAL ESTADO E POLÍTICAS SOCIAIS NO BRASIL,2003. Cascavel. Anais [...]. Cascavel: Unioeste, 2003.

DIESEL, Aline; BALDEZ, Alda Leila Santos; MARTINS, Silvana Neumann. Os princípios das metodologias ativas de ensino: uma abordagem teórica. Revista Thema, Pelotas, v. 14, $\mathrm{n}^{\circ}$ 1, p. 268-288, 2017.

FREIRE, Paulo. Pedagogia da Autonomia: saberes necessários à prática educativa. $51^{\mathrm{a}} \mathrm{ed}$. Rio de Janeiro: Paz e terra, 2015.

GEMIGNANI, Elizabeth Yu Me Yut. Formação de professores e metodologias ativas de ensino-aprendizagem: Ensinar para a compreensão. Revista Fronteira das Educação [online], Recife, v. 1, n. 2, 2012. Disponível em: http://www.fronteirasdaeducacao.org/index.php/fronteiras/article/view/14 Acesso em 18 de nov de 2018.

GIL, Antônio Carlos. Métodos e técnicas de pesquisa social. $5^{\text {a }}$ ed. São Paulo: Atlas, 1999. HEINSFELD, Bruna Damiana; PISCHETOLA, Magda. Cultura digital e educação, uma leitura dos estudos culturais sobre os desafios da contemporaneidade. Revista IberoAmericana de Estudos em Educação, Araraquara, v. 12, n. esp. 2, p. 1349-1371, ago., 2017. Disponível em: https://periodicos.fclar.unesp.br/iberoamericana/article/view/10301. Acesso em: 29 mar 2019.

LIBÂNEO, José Carlos. Democratização da escola pública: a pedagogia crítico-social dos conteúdos. São Paulo: Loyola; 2009.

LIMA, Valéria Vernaschi. Espiral construtivista: uma metodologia ativa de ensinoaprendizagem. Interface, Botucatu, v. 21, n. 61, p 421-434. Abr./jun. 2017.

LOVATO, Fabricio Luís; et. al. Metodologias Ativas de Aprendizagem: uma breve revisão. Acta Scientiae, Canoas, v.20, n.2, p.154-171, mar./abr. 2018. Disponível em: http://www.periodicos.ulbra.br/index.php/acta/article/viewFile/3690/2967 Acesso em 16 nov. de 2018.

MAZUR, Eric. Peer Instruction: a revolução da aprendizagem ativa. Porto Alegre: Penso, 2015.

MELO, Rafaela da Silva; BOLL, Cintia Inês. Cultura Digital e Educação: desafios contemporâneos para a aprendizagem escolar em tempos de dispositivos móveis. RENOTE Novas tecnologias na educação, Porto Alegre, v. 12, n. 1, julho, 2014. 
MILL, D. (org.). Dicionário crítico de educação e tecnologias e de educação a distância Campinas, SP: Papirus, 2018.

MORÁN, José. Mudando a educação com metodologias ativas. In: SOUZA, Carlos Alberto de; MORALES, Ofelia Elisa Torres (orgs.). Convergências midiáticas, educação e cidadania: aproximações jovens. Vol. II. Ponta Grossa, UEPG/PROEX, 2015. p. 15-33.

PAIVA, Marlla Rúbya Ferreira, et al. Metodologias ativas de ensino-aprendizagem: revisão integrativa. SANARE, Sobral, v.15 n.02, p.145-153, jun./dez. 2016. Disponível em: https://sanare.emnuvens.com.br/sanare/article/view/1049/595. Acesso em: 25 abr. 2019.

PETRIS, Vânia Fuchter. O desafio da educação na cultura digital. 2016. Trabalho de Conclusão de Curso (Especialização em Educação na Cultura Digital) - Universidade Federal de Santa Catarina, Santa Catarina, 2016. Disponível em:

https://repositorio.ufsc.br/xmlui/bitstream/handle/123456789/169813/TCC_Petris.pdf?sequen ce=1\&isAllowed=y Acesso em: 29 mar 2019 .

POZO, Juan Ignacio; CRESPO, Miguel Ángel Gómez. A aprendizagem e o ensino de ciências: do conhecimento cotidiano ao conhecimento científico. Tradução Naila Freitas. 5.ed. Porto Alegre: Artmed, 2009.

PUGLIESE, Gustavo Oliveira. Os modelos pedagógicos de ensino de ciências em dois programas educacionais baseados em STEM (Science, Technology, Engineering and Mathematics). 2017. Dissertação (Mestrado em Genética e Biologia Molecular) - Instituto de Biologia, Universidade Estadual de Campinas, Campinas, 2017. Disponível em: http://repositorio.unicamp.br/bitstream/REPOSIP/331557/1/Pugliese_GustavoOliveira_M.pdf Acesso em: 20 maio 2019.

RAMOS, Wilsa Maria; BOLL, Cintia Inês. A Cultura Digital e os novos Contextos de Aprendizagem: quem sabe como e onde eu aprendo sou. In: TRINDADE, Sara Dias; MILL, Daniel (Org.). Educação e humanidades digitais: aprendizagens, tecnologias e cibercultura. Coimbra - Portugal: Imprensa da Universidade de Coimbra, 2019, v. 1, p. 5170.

SAVIANI, Dermeval. Escola e democracia. 41 a ed. Campinas: Autores Associados; 2009.

SILVA, Iatiçara Oliveira, et al. Educação Científica empregando o método STEAM e um makerspace a partir de uma aula-passeio. Latin American Journal of Science Education, Matanzas, v.4, n.2, nov. 2017. Disponível em: https://docplayer.com.br/126524825-Latinamerican-journal-of-science-education-educacao-cientifica-empregando-o-metodo-steam-eum-makerspace-a-partir-de-uma-aula-passeio.html Acesso em: 27 abr 2019.

SOUZA, Samir Cristino de; DOURADO, Luis. Aprendizagem baseada em problemas (ABP): um método de aprendizagem inovador para o ensino educativo. HOLOS, Natal, v. 5, p. 182200. 2015.

VALENTE, José Armando; ALMEIDA, Maria Elizabeth Bianconcini de; GERALDINI, Alexandra Fogli Serpa. Metodologias ativas: das concepções às práticas em distintos níveis de ensino. Revista Diálogo Educacional, Curitiba, v. 17, n. 52, p. 455-478, abr./jun. 2017. 
Disponível em:

https://periodicos.pucpr.br/index.php/dialogoeducacional/article/viewFile/9900/12386 . Acesso em: 18 mar. 2019.

VALENTE, José Armando. Blended learning e as mudanças no ensino superior: a proposta da sala invertida. Educar em Revista, Curitiba, Brasil, Edição Especial n. 4/2014, p. 79-97.

ZALUSKI, Felipe Cavalheiro; OLIVEIRA, Tarcisio Dorn. Metodologias ativas: uma reflexão teórica sobre o processo de ensino e aprendizagem. CIET:EnPED, [S.1.], maio 2018. ISSN 2316-8722. Disponível em:

https://cietenped.ufscar.br/submissao/index.php/2018/article/view/556. Acesso em: 11 nov. 2018.

Recebido em junho de 2019.

Aprovado em outubro de 2019. 